Gender achievement and social, political and economic equality: a European perspective

Professor Gren Ireson

Professor of Science Education

Nottingham Trent University,

Clifton Campus,

Nottingham NG11 8NS,

UK 


\title{
Gender achievement and social, political and economic equality: a European perspective
}

\begin{abstract}
Differences in gender equality based on social, political and economic factors is cited, by some writers, as a contributory factor in the differentially greater achievement of boys in STEM subjects through the concept of gender stratification. Gender differences, especially in mathematics, have been linked directly to gender parity in wider society. Such a link is predicted by gender stratification via both the gender similarities and gender stratification hypotheses, for example (Else-Quest et al. 2010 and Hyde and Mertz, 2009) . Analysis by Ainara González de San Román \& Sara de la Rica Goiricelaya (2012) appears to support the hypothesis that the gender gap is smaller, in mathematics, when the society has a higher equality index. However, more recently, Stoet \& Geary (2015) report evidence, based on PISA outcomes from 2000 to 2009, that there is little or no correlation between the gender gap and wider equality. This paper takes up this analysis using PISA data from the 2012 round, for both science and mathematics, and the Global Gender Gap Index in a European context. The results support Stoet \& Geary's findings and cast doubts on any link between national gender equality and achievement in science or mathematics. Whilst the conclusion reached in this paper supports Stoet \& Geary's findings further work is needed to explain the observed differences in achievement between boys and girls.
\end{abstract}

\section{Introduction}

Boys do better at mathematics and girls do better at reading and writing. This appears to be the consensus that has remained stable for the past hundred years (Voyer \& Voyer, 2014). Indeed it could be argued that John Locke hinted at this over 320 years ago, (Locke, 1693) when discussing the perceived ease with which girls master a second language compared to their male peers.

Current literature provides an argument that gender differences are stable, narrowing or effectively closed. The narrowing is mostly discussed via social change and greater gender equality in wider society. Whilst much of the literature focuses on gender differences in mathematics, as do Stoet \& Geary (2015), rather than science or overall achievement. Gender stratification, offers an hypothesis that gender differences in society result in gender differences in mathematical achievement (Guiso et al., 2008). Drawing on such a theoretical, causal, model a link between gender equality in wider society and gender differences in mathematics and science achievement educational outcomes:

The gender similarities hypothesis: this hypothesis is generally credited to Janet Hyde, based on a meta-analysis of over 2000 studies states that "males and females are alike on most- but not all-psychological variables" leading to a conclusion that a focus on sex differences "underestimates girls performance in mathematics" (Hyde, 2005).

The gender stratification hypothesis: this hypothesis argues that gender differences in, for example mathematics and science, "reflect gender inequalities in educational and economic opportunities in a given culture" Else-Quest et al (2010).

The gender similarities and gender stratification hypotheses taken together, whether one looks at the level of the group or the individual, propose gender differences are the result of wider societal factors, e.g. social, political and economic equality. Thus these factors would be expected to impact on gender differences in educational achievement. 
The author of this paper does not hold a view either for or against gender stratification in society and its impact on educational achievement. Rather he wishes to follow contemporary data and see where these data lead in terms of gender equality and achievement focusing on Science and Mathematics. Asking the question as to whether gender equality can be correlated with achievement in Science and Mathematics.

In the analysis presented in this paper a European perspective is taken since previous work, e.g. (SECURE, 2013), demonstrates a high degree of similarity between both education systems and curriculum content across Europe.

\section{Methodology}

This paper draws on two data sets, the PISA (2012) results and the Global Gender Gap Report (2014) both of which are in the public domain and hence available for further scrutiny. Given the provenance of both measures and their use in literature they are taken to be both reliable and robust data sources. This allows correlations to be explored with a degree of reliability and validity.

If gender stratification is to have predictive power over or support a causal link between wider societal equality and educational achievement then a correlation between a measurement of equality and a measure of educational achievement is to be expected. Whilst finding a correlation, regardless of its strength, cannot be taken as a causal link the absence of a correlation would refute a causal link.

\section{Pisa data}

PISA 2012: The Organisation for Economic Co-operation and Development (OECD) collect data for 15 year old learners, defined as between 15 years 3 months and 16 years and 2 months, across a reading, mathematics and science across 65 countries. In each participating country a representative sample of students, from a representative sample of schools, then take the test (OECD, 2014a). The 2012 cohort sampled 510000 students representing approximately 28000000 fifteen year old learners across the participating countries (OECD, 2014a), using probability proportion to size (PPS) sampling (OECD, 2014b). If equally divided this would suggest approximately 7800 students per participating country, however PISA report between 4500 and 10000 per participating country (OECD, 2003) following PPS.

The core PISA scores from mathematics, science and reading are transformed to a mean value of a 500 point PISA score in each participating country. Within this paper the transformed PISA point scores for each country are recorded for Science and Mathematics allowing any gender gap to be seen.

\section{Gender Equality data}

Global Gender Gap Index [GGGI]: The World Economic Forum (WEF), publishes the GGGI on an annual basis measuring the gender equality on a 0 to 1 scale drawing on four key indicators of health, politics, economy and education. Data in this paper are taken from the 2014 GGGI report (WEF, 2014). Since the GGGI was first introduced in 2006 the data set used in this paper is argued to be based on a robust methodology which when taken with the evidence of little change over time, except in Nordic countries which have shown a steady improvement, provides a measure of stability in the data. 
variation in overall equality index

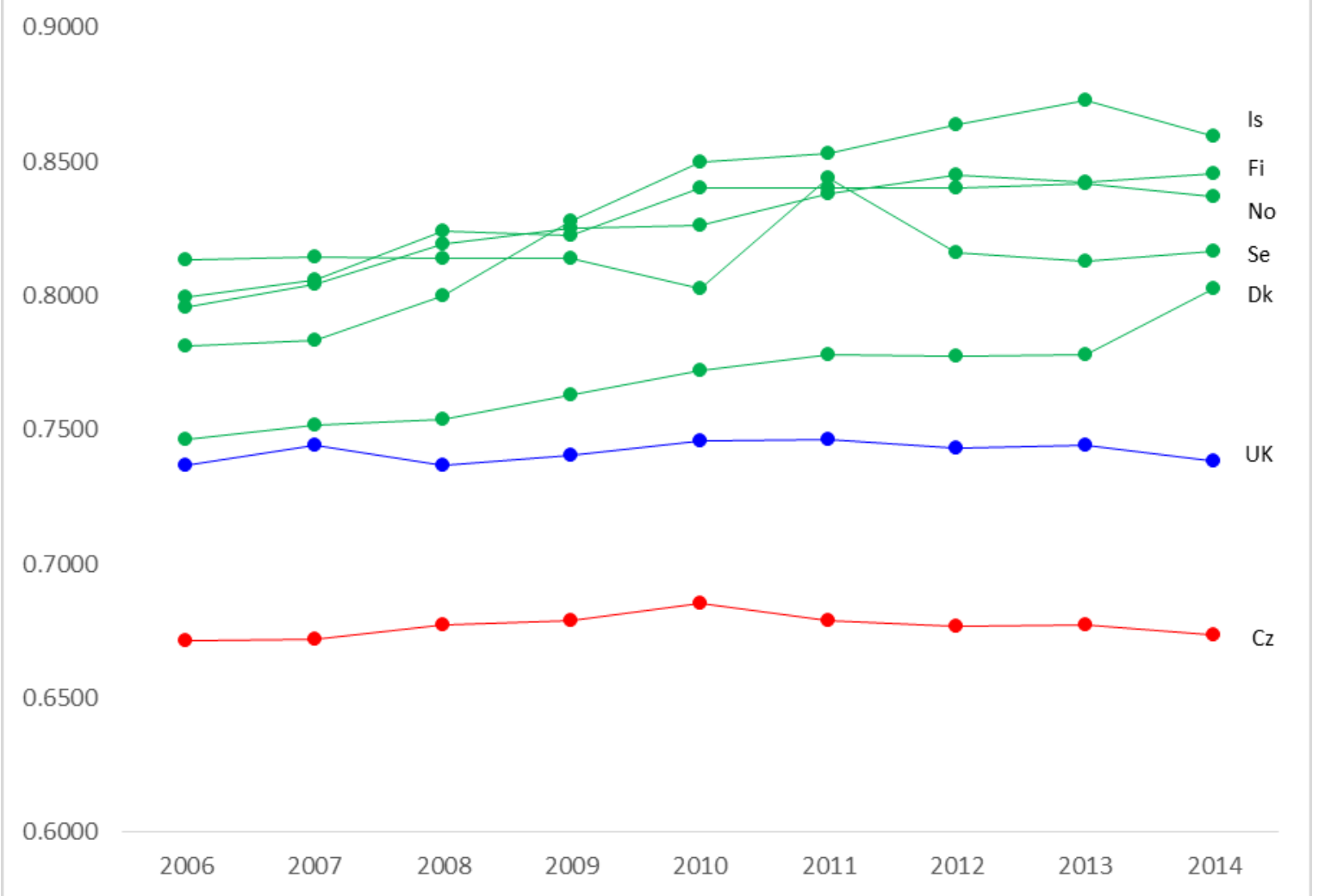

Figure 1 variation of overall global equality index 


\begin{tabular}{|c|c|c|}
\hline \multirow{2}{*}{ country } & \multicolumn{2}{|c|}{ GGI 2006-14 } \\
\cline { 2 - 3 } & mean & s.d. \\
\hline Iceland & 0.8324 & 0.0357 \\
\hline Finland & 0.8269 & 0.0179 \\
\hline Norway & 0.8280 & 0.0161 \\
\hline Sweden & 0.8164 & 0.0112 \\
\hline Denmark & 0.7692 & 0.0175 \\
\hline Ireland & 0.7669 & 0.0196 \\
\hline Belgium & 0.7420 & 0.0273 \\
\hline Germany & 0.7566 & 0.0112 \\
\hline Netherlands & 0.7493 & 0.0150 \\
\hline France & 0.7080 & 0.0313 \\
\hline Slovenia & 0.6880 & 0.0213 \\
\hline United Kingdom & 0.7417 & 0.0039 \\
\hline Spain & 0.7376 & 0.0121 \\
\hline Austria & 0.7176 & 0.0158 \\
\hline Portugal & 0.7070 & 0.0102 \\
\hline Poland & 0.6964 & 0.0110 \\
\hline Estonia & 0.7013 & 0.0047 \\
\hline Italy & 0.6743 & 0.0167 \\
\hline Slovakia & 0.6809 & 0.0032 \\
\hline Greece & 0.6740 & 0.0121 \\
\hline Hungary & 0.6740 & 0.0064 \\
\hline Czech Republic & 0.6767 & 0.0042 \\
\hline & & \\
\hline
\end{tabular}

Table 1 mean and standard deviation for overall global equality index

\section{Effect size}

The effect size, as is the expectation in such studies, for boys' achievement beyond girls' achievement is reported using Cohen's $d$, with 0.20 taken as a 'small' effect and 0.5 a 'medium' effect (Cohen, 1977). Taking this value it can be seen that only the mathematics value for Austria is above the 'cut off'.

However as Baguley (2009) writes 'for standardised measures in the $d$ family of effect size metrics it is difficult to imagine situations in which the goals of the researcher could not be met using a simple difference in means'. To this end the 'simple difference in means' is used in this paper. The metric used is the gender gap, taken to be the mean boys score - the mean girls score.

Taking the two data sources together allows for the data set used in the analysis to be presented as in table 2 below. 


\begin{tabular}{|c|c|c|c|c|c|c|c|c|}
\hline \multirow[t]{2}{*}{ Country } & \multirow{2}{*}{$\begin{array}{c}\text { overall } \\
\text { equality } \\
\text { index }\end{array}$} & \multicolumn{2}{|c|}{$\begin{array}{l}\text { PISA } 2012 \\
\text { Science }\end{array}$} & \multirow{2}{*}{$\begin{array}{l}\text { Effect } \\
\text { size } d\end{array}$} & \multicolumn{2}{|c|}{$\begin{array}{c}\text { PISA } 2012 \\
\text { Mathematics }\end{array}$} & \multirow{2}{*}{$\begin{array}{l}\text { Effect } \\
\text { size } d\end{array}$} & \multirow{2}{*}{$\begin{array}{c}\text { overall } \\
\text { gender } \\
\text { gap }\end{array}$} \\
\hline & & boys & girls & & boys & girls & & \\
\hline Iceland & 0.8594 & 477 & 480 & -0.030 & 490 & 496 & -0.060 & -9 \\
\hline Finland & 0.8453 & 537 & 554 & -0.170 & 517 & 520 & -0.030 & -20 \\
\hline Norway & 0.8370 & 493 & 496 & -0.030 & 490 & 488 & 0.020 & -1 \\
\hline Sweden & 0.8165 & 481 & 489 & -0.080 & 477 & 480 & -0.030 & -11 \\
\hline Denmark & 0.8025 & 504 & 493 & 0.110 & 507 & 493 & 0.140 & 25 \\
\hline Ireland & 0.7850 & 524 & 520 & 0.040 & 509 & 494 & 0.150 & 19 \\
\hline Belgium & 0.7809 & 507 & 503 & 0.040 & 520 & 509 & 0.110 & 15 \\
\hline Germany & 0.7780 & 524 & 524 & 0.000 & 520 & 507 & 0.130 & 13 \\
\hline Netherlands & 0.7730 & 524 & 520 & 0.040 & 528 & 518 & 0.100 & 14 \\
\hline France & 0.7588 & 498 & 500 & -0.020 & 499 & 491 & 0.080 & 6 \\
\hline Slovenia & 0.7443 & 510 & 519 & -0.090 & 503 & 499 & 0.040 & -5 \\
\hline United Kingdom & 0.7383 & 521 & 508 & 0.130 & 500 & 488 & 0.120 & 25 \\
\hline Spain & 0.7325 & 500 & 493 & 0.070 & 492 & 476 & 0.160 & 23 \\
\hline Austria & 0.7266 & 510 & 501 & 0.090 & 517 & 494 & 0.230 & 32 \\
\hline Portugal & 0.7243 & 488 & 490 & -0.020 & 493 & 481 & 0.120 & 10 \\
\hline Poland & 0.7051 & 524 & 527 & -0.030 & 520 & 516 & 0.040 & 1 \\
\hline Estonia & 0.7017 & 540 & 543 & -0.030 & 523 & 518 & 0.050 & 2 \\
\hline Italy & 0.6973 & 495 & 492 & 0.030 & 494 & 476 & 0.180 & 21 \\
\hline Slovakia & 0.6806 & 475 & 467 & 0.080 & 486 & 477 & 0.090 & 17 \\
\hline Greece & 0.6764 & 460 & 473 & -0.130 & 457 & 449 & 0.080 & -5 \\
\hline Hungary & 0.6759 & 496 & 493 & 0.030 & 487 & 473 & 0.140 & 17 \\
\hline Czech Republic & 0.6737 & 509 & 508 & 0.010 & 505 & 493 & 0.120 & 13 \\
\hline
\end{tabular}

Table 2 data set used in the following analysis

\section{Results}

The initial analysis is focused on the correlation between GGGI and the overall gender gap from table 2 .

Whilst some slight trend towards the overall gender gap favouring girls with an increased equality index, $r=-0.403, p=0.063$, it is 'weak' using the Peck \& Devore (2012) criteria and not significant at the 0.05 level. With $r^{2}=0.1624,16.24 \%$ of the variance is explained by the linear model which further supports the 'weakness'. 


\section{GGGI and overall gender gap}

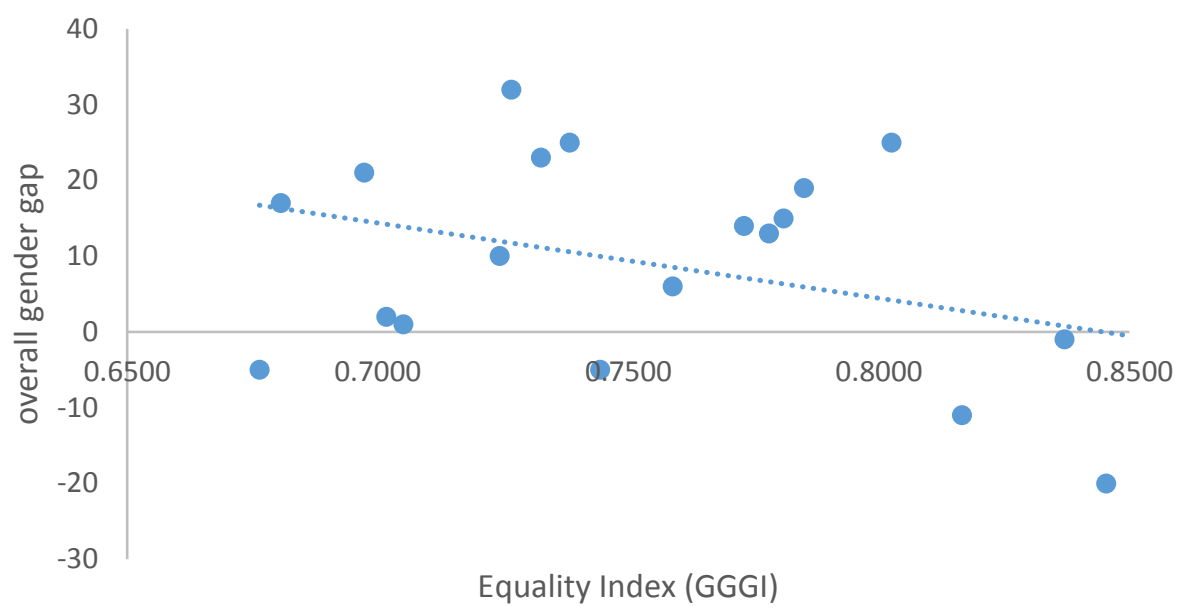

$r=-0.403, p=0.063$

\section{Figure 2 GGGI v overall gender gap}

In an approach that involves regression analysis, as this paper does, it is common to also assess the influence of the measures to identify outliers. To this end Cook's distance, D, was calculated for overall gender gap (combining both the science and mathematics scores from PISA), the science gender gap and the mathematics gender gap. The cut off point for Cook's D can be taken to be 4/N (Bollen \& Jackman, 1990) or the more robust $4 /(\mathrm{N}-\mathrm{k}-1)$ (Cook and Weisberg, 1982), giving 0.18 in the former and 0.20 in the latter case.

The only potential points for exclusion, i.e. values above the cut-off, following this are:

Greece, overall difference, 0.31

Finland, overall difference, 0.51

Finland, Science difference, 0.45

Finland, Mathematics difference, 0.22

However if the GGGI and the overall gender gap correlation is calculated without Finland $r=-0.128$ and $p=0.570$, explaining only $1.64 \%$ of the variance. To avoid this effect on the data set it was decided to retain Finland in all further analyses. 


\section{GGGI and overall gender gap [without Finland]}

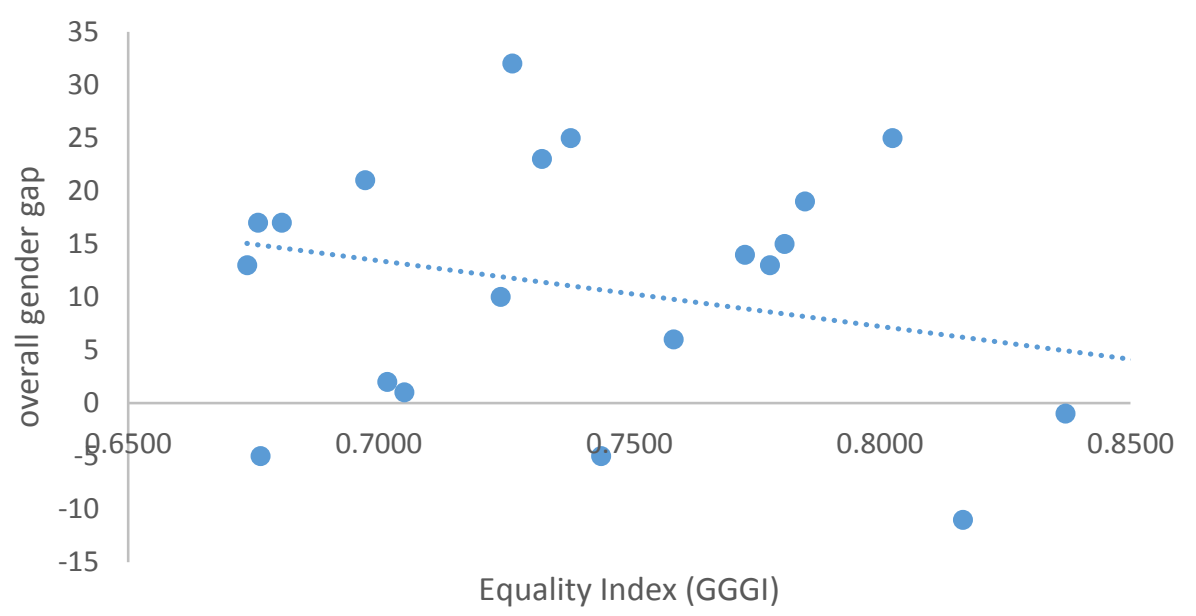

$r=-0.128, p=0.570$

Figure 3 GGGI v overall gender gap excluding Finland

Having accepted that Finland will be maintained the analysis takes the form of the relation between the equality measure (GGGI) and the gender gap in science, the equality measure and gender gap in mathematics and the equality measure and overall gender gap.

\section{The gender gap in science}

GGGI and science gender gap

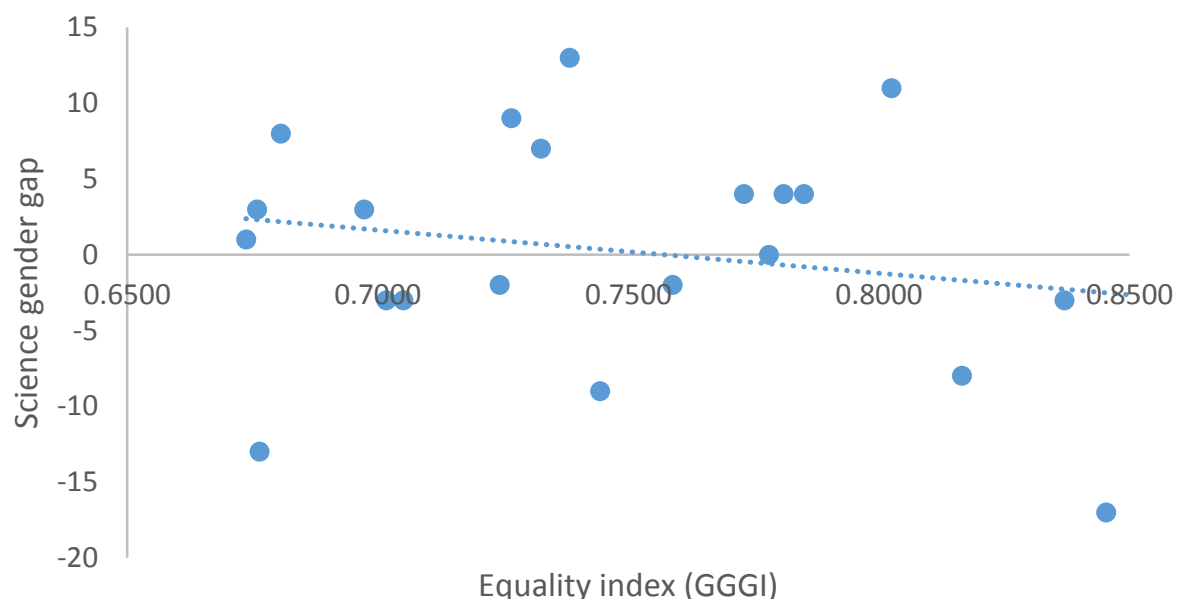

Equality index (GGGI)

$r=-0.217, p=0.332$

Figure 4 GGGI and Science gender gap

As shown in figure 4, with $r=-0.217$, suggests a weak correlation using either the Evans or Peck \& Devore criteria. 


\section{The gender gap in mathematics}

\section{GGGI and mathematics gender gap}

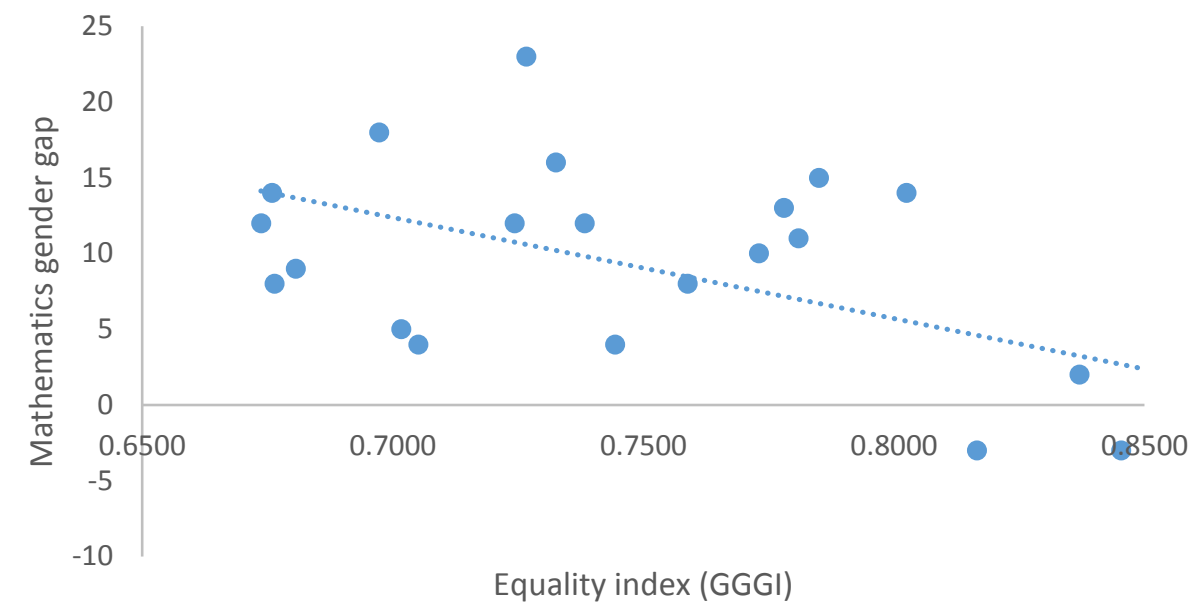

$r=-0.533, p=0.013$

Figure 5 GGGI and mathematics gender gap

As shown in figure 5 , with $r=-0.533$, suggests a moderate correlation using either the Evans or Peck \& Devore criteria

\section{The overall gender gap}

As shown in figure 2, the correlation between the overall gender gap and the equality index is weak. Even taking the 'moderate' interpretation of $r=0.403$, Evans (1996), the value is on the cusp of the 0.39 category. The lack of significance at the 0.05 level suggests we can attach little strength to a link between the equality index and the overall gender gap.

In dealing with science and mathematics, or more broadly STEM, some specific indicators may be seen as contributory. Gender gaps from the PISA results were therefore compared with the percentage of females in STEM based research and the percentage of females in the country's parliament. In addition the school starting age in each country was considered, since evidence suggests attitudes to science become fixed at an early age, for example Turner and Ireson (2010). One difference that stands out amongst European countries is the number of compulsory tests and these were also compared. The results of these analyses are given in table 3 below. 


\begin{tabular}{|c|c|c|c|c|c|}
\hline & $\begin{array}{l}\text { \% females } \\
\text { in STEM } \\
\text { research }\end{array}$ & $\begin{array}{l}\% \text { females } \\
\text { in } \\
\text { parliament }^{2}\end{array}$ & $\begin{array}{l}\text { School } \\
\text { starting } \\
\text { age }^{3}\end{array}$ & $\begin{array}{l}\text { Number of } \\
\text { compulsory } \\
\text { tests }^{4}\end{array}$ & $\begin{array}{c}\text { Number of } \\
\text { compulsory } \\
\text { tests } \\
\text { [excluding }_{\text {Denmark] }}^{5}\end{array}$ \\
\hline GGGI & $\begin{array}{l}r=-0173 \\
p=0.441\end{array}$ & $\begin{array}{l}r=0.730 \\
p<0.001\end{array}$ & $\begin{array}{l}r=-0.045 \\
p=0.842\end{array}$ & $\begin{array}{l}r=0.358 \\
p=0.102\end{array}$ & $\begin{array}{l}r=0.347 \\
p=0.123\end{array}$ \\
\hline $\begin{array}{c}\text { Science } \\
\text { Gender Gap }\end{array}$ & $\begin{array}{l}r=-0.070 \\
p=0.757\end{array}$ & $\begin{array}{l}r=-0.192 \\
p=0.392\end{array}$ & $\begin{array}{l}r=-0.513 \\
p=0.015\end{array}$ & $\begin{array}{l}r=0.267 \\
p=0.230\end{array}$ & $\begin{array}{l}r=0.005 \\
p=0.989\end{array}$ \\
\hline $\begin{array}{c}\text { Mathematics } \\
\text { Gender Gap }\end{array}$ & $\begin{array}{l}r=-0.313 \\
p=0.360\end{array}$ & $\begin{array}{l}r=-0.372 \\
p=0.088\end{array}$ & $\begin{array}{l}r=-0.437 \\
p=0.042\end{array}$ & $\begin{array}{l}r=-0.048 \\
p=0.832\end{array}$ & $\begin{array}{l}r=-0.313 \\
p=0.167\end{array}$ \\
\hline $\begin{array}{c}\text { Overall } \\
\text { Gender Gap }\end{array}$ & $\begin{array}{l}r=-0.205 \\
p=0.360\end{array}$ & $\begin{array}{l}r=-0.303 \\
p=0.170\end{array}$ & $\begin{array}{l}r=-0.516 \\
p=0.014\end{array}$ & $\begin{array}{l}r=0.123 \\
p=0.586\end{array}$ & $\begin{array}{l}r=-0.167 \\
p=0.469\end{array}$ \\
\hline
\end{tabular}

Table 3; exploring additional factors which may contribute to the gender gap, significant values [p $=0.05]$ shown in bold

Since women's involvement in politics is part of the GGGI metric the 'strong' correlation, 0.730 between the percentage of women in parliament and the GGI and the high significance, $p<0.001$ is to be expected.

However, three other significant correlations can be seen between the school starting age and the Science Gender Gap, the Mathematics Gender Gap and the Overall Gender Gap. In each case the trend is a later starting age supports girls' achievement in maths and science. Obviously with fifteen of the twenty two countries having the same starting age this is open to debate.

If the same analysis is run using all PISA participating countries, the correlation trend with school starting age remains but the significance is lost at the 0.05 level:

Science Gender Gap, $r=-0.221, p=0.092$

Mathematics Gender Gap, $r=-0.216, p=0.084$

Overall Gender Gap, $r=-0.231, p=0.071$

\section{Discussion}

The main finding of these analyses is that there is no reliable evidence of a relationship between gender equality and achievement in science or mathematics. This supports the conclusion drawn, using earlier data sets, by Stoet and Geary (2015), which suggests no correlational link between the gender gap and equality index, and counter to the conclusions of de San Román and de la Rica (2012) which suggests the gender gap in mathematics, is smaller when the society has a higher equality index.

From a theoretical perspective other authors, for example Else-Quest (2010) and Reilly (2012) have drawn on sociological/psychological theories of both gender similarity and

\footnotetext{
${ }^{1}$ European Commission (2012)

2 IPU (2015)

${ }^{3}$ EACEA (2009)

${ }^{4}$ EACEA (2009)

${ }^{5}$ With 10 compulsory tests Denmark can be considered an outlier in this category with the next highest being four and the modal value being one.
} 
gender stratification to articulate a predicted differential achievement especially in mathematics.

Whilst the conclusions of those studies which did find a correlational link between gender equality and PISA outcomes for boys and girls must be accepted, these studies have focused on the PISA 2003 data set. For a link to be established, even at a correlational level, one would expect to see some degree of consistency over time and both this analysis, using PISA 2012 data and that of Stoet and Geary (2015), using PISA 2006 and 2009 data, find this not to be the case.

Hence, notwithstanding the fact that previous studies have focused on achievement in mathematics, I argue the evidence suggests that there is no link between gender equality and achievement in either mathematics or science through the analysis of the overall gender gap as defined above.

In considering the GGGI values it is obvious that the Nordic countries occupy the top five places but is there a Nordic cluster? A cluster analysis of PISA data from the 2003 round, Olsen (2005), suggests that a unique Nordic cluster does not exist.

In this analysis a similar cluster analysis was undertaken using a 2 to 6 Cluster model the resulting cluster table is shown below in table 4.

Cluster Membership

\begin{tabular}{|c|c|c|c|c|c|}
\hline Case & 6 Clusters & 5 Clusters & 4 Clusters & 3 Clusters & 2 Clusters \\
\hline 1:Iceland & 1 & 1 & 1 & 1 & 1 \\
\hline 2:Finland & 1 & 1 & 1 & 1 & 1 \\
\hline 3:Norway & 1 & 1 & 1 & 1 & 1 \\
\hline 4:Sweden & 2 & 2 & 2 & 2 & 1 \\
\hline 5:Denmark & 2 & 2 & 2 & 2 & 1 \\
\hline $6:$ Ireland & 3 & 3 & 2 & 2 & 1 \\
\hline 7:Belgium & 3 & 3 & 2 & 2 & 1 \\
\hline 8:Germany & 3 & 3 & 2 & 2 & 1 \\
\hline 9:Netherlands & 3 & 3 & 2 & 2 & 1 \\
\hline 10:France & 3 & 3 & 2 & 2 & 1 \\
\hline 11:Slovenia & 4 & 4 & 3 & 3 & 2 \\
\hline 12:United Kingdom & 4 & 4 & 3 & 3 & 2 \\
\hline 13:Spain & 4 & 4 & 3 & 3 & 2 \\
\hline 14:Austria & 4 & 4 & 3 & 3 & 2 \\
\hline 15:Portugal & 4 & 4 & 3 & 3 & 2 \\
\hline 16:Poland & 5 & 5 & 4 & 3 & 2 \\
\hline 17:Estonia & 5 & 5 & 4 & 3 & 2 \\
\hline 18:Ialy & 5 & 5 & 4 & 3 & 2 \\
\hline 19:Slovakia & 6 & 5 & 4 & 3 & 2 \\
\hline 20:Greece & 6 & 5 & 4 & 3 & 2 \\
\hline 21:Hungary & 6 & 5 & 4 & 3 & 2 \\
\hline 22:Czech Republic & 6 & 5 & 4 & 3 & 2 \\
\hline
\end{tabular}

Table 4 Cluster membership for GGGI using a 2, 3, 4, 5 or 6 Cluster model 
With the dendrogram generated in the analysis shown in figure 6.

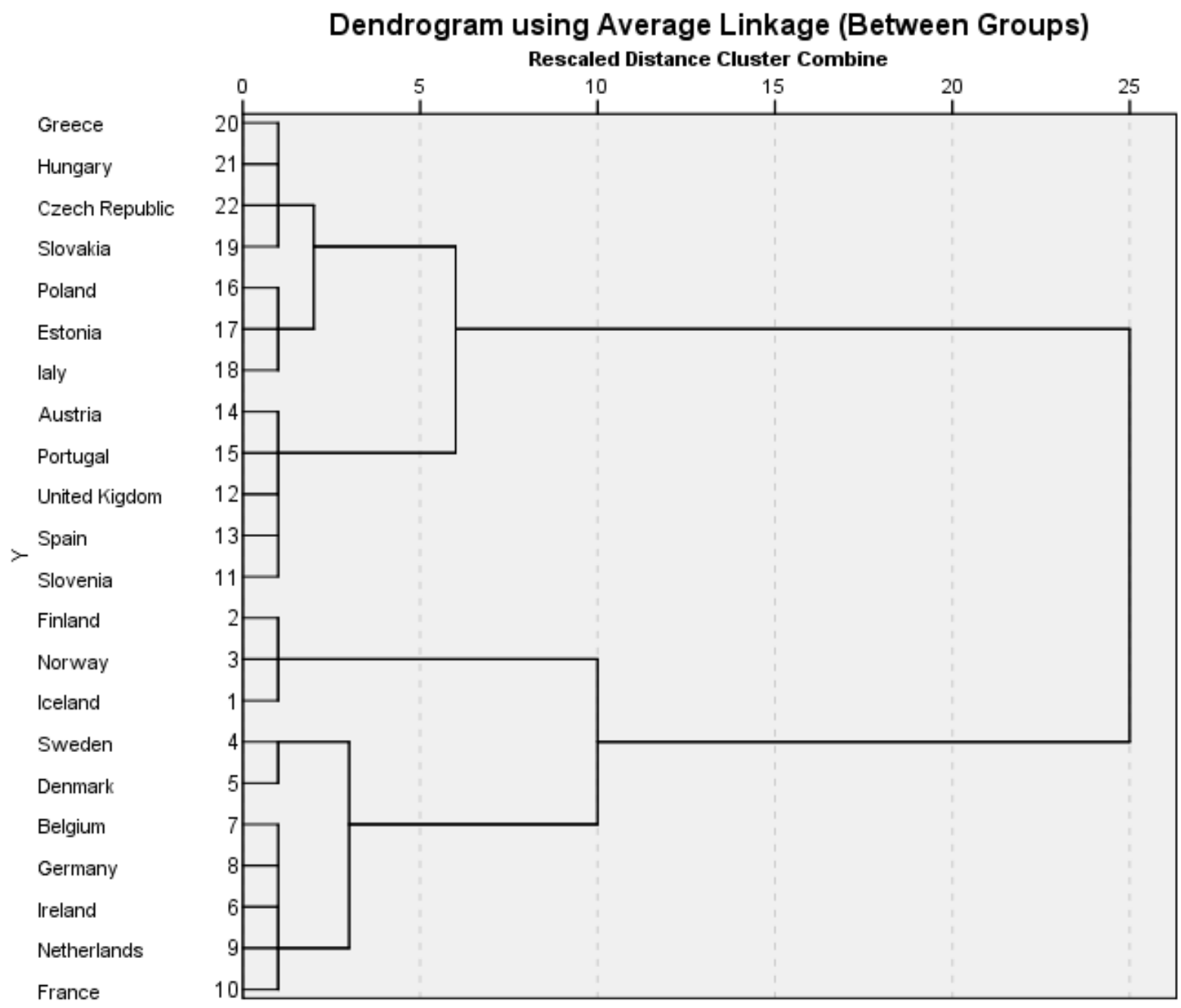

Figure 6 Dendrogram using GGGI

There is no simple Nordic cluster but in a five or six cluster model one could argue the case for two Nordic clusters. Nordic 1 Iceland, Finland and Norway and Nordic 2 Sweden and Denmark

Whilst this analysis, and others, have found no link between gender equality and achievement in science and mathematics it is still the case that the data show a large range in overall gender gap from -20 in Finland with girls outperforming boys to +32 in Austria with boys outperforming girls. Having established the lack of a correlational link the impact of the research on policy should be that we cannot assume that greater gender equality, across a basket of social, economic and political measures, will lead to an equality of performance against an international measure. Other factors impacting on gender differences in Science and Mathematics, or any other subject, need to be considered. For example career interest (Rounds \& Rong, 2014). Stoet and Geary (2015) further note that stratification hypotheses can be questioned for assigning 'male' and 'female' as "all or none" categorical variables. This issue is explored in Joel et al (2015). 


\section{Conclusion}

The key conclusion from the above analysis is that, supportive of Stoet and Geary (2015) using the PISA 2009 data, there is no statistically significant correlation between GGI and the mathematics, science or overall gender gap. These findings are at odds with both the gender stratification and gender similarities hypotheses.

What this means for curriculum developers and policy, both educational and social, makers is that they must not expect greater social, economic and political equality to result in greater equality of educational achievement in science and mathematics.

I will not reiterate the vast volume of literature that has been produced investigating engagement, retention and under/over recruitment in STEM subjects but rather pose a new area of investigation. Since gender equality appears not to impact on the overall gender gap and despite numerous interventions the gender differences have existed over time could it be that girls/boys are not anti-STEM but simply more pro-other subjects? 


\section{References}

Baguley, T (2009) Standardized or simple effect size: What should be reported? British Journal of Psychology 100 pp 603-617

Bollen, K A. and Jackman, R W. (1990); Regression diagnostics: An expository treatment of outliers and influential cases, in Fox, J and Long, J. S (eds.); Modern Methods of Data Analysis. Newbury Park, CA: Sage

Cohen, J. (1977). Statistical power analysis for the behavioural sciences. New York, Routledge

Cook, R. Dennis; and Weisberg, Sanford (1982); Residuals and influence in regression, New York, NY: Chapman \& Hall

EACEA (2009); Eurydice National Testing of Pupils in Europe: Objectives, Organisation and Use of Results Brussels: Eurydice

Else-Quest, N. M., Hyde, S. J. \& Linn, M. C. (2010) Cross-national patterns of gender differences in mathematics: a meta-analysis, Psychological Bulletin 1361 pp 103127

European Commission (2012) She Figures 2012 Gender in Research and Innovation, Brussels: European Commission

Evans, J. D. (1996). Straightforward statistics for the behavioural sciences. Pacific Grove, CA: Brooks/Cole Publishing

González de San Román, A and de la Rica, S (2012), Gender Gaps in PISA Test Scores: The Impact of Social Norms and the Mother's Transmission of Role Attitudes. IZA Discussion Paper No. 6338. Available at http://ssrn.com/abstract=2007329 [accessed 09.10.2015]

Guiso, L., Monte, F., Sapienza, P. \& Zingales, L (2008) Gender, culture and math, Science 3205880 pp 1164-1165

Hyde, J., S. (2005) The Gender Similarities Hypothesis, American Psychologist 606 pp 581-592

Hyde, J. S. and Mertz, J. E. (2009) Gender, culture, and mathematics performance, Proceeding of the National Academy of Sciences, 10622 pp 8801-8807

IPU (2015) Inter Parliamentary Union Women in Parliaments: World Classification. Available at http://www.ipu.org/wmn-e/classif.htm [accessed 03.11.2015] 
Joel, D., Berman, Z., Tavor, I., Wexler, N., Gaber, O., Stein, Y., Shefi, N., Pool, J., Urchs, S., Marguilies, D. S., Liem, F., Hanggi, J., Jancke, L. \& Assaf, Y. (2015), Sex beyond the genitalia: The human brain mosaic, Proceeding of the National Academy of Sciences 11250 pp 15468-15473

Locke, J (1693) Some Thought Concerning Education, A J Churchill, London.

OECD (2003) The PISA 2003 assessment framework, OECD Publishing, Paris

OECD (2014a) PISA 2012 Results in Focus: What 15-year-olds and what they can do with what they know, OECD Publishing, Paris

OECD (2014b) PISA 2012 Technical Report, OECD Publishing, Paris

Olsen, R., V. (2005) An exploration of cluster structure in scientific literacy in PISA: Evidence for a Nordic dimension?, Nordic Studies in Science Education, 1 pp. 81-94

Reilly, D (2012) Gender, culture and sex-typed cognitive abilities, PLoS One, available at

http://journals.plos.org/plosone/article?id=10.1371/journal.pone.0039904 [assessed, 16.12.2015]

Rounds, J. \& Rong, S. (2014) The Nature and Power of Interests, Current Directions in Psychological Science 232 pp 98-103

Stoet, G and Geary, D. C (2015) Sex differences in academic achievement are not related to political, economic or social equality, Intelligence, 48 pp 137-151

Turner, S and Ireson, G (2010) Fifteen pupils' positive approach to primary school science: when does it decline? Educational Studies 262 pp119-141

Peck, R \& Devore, J. L (2012) Statistics: The Exploration \& Analysis of Data, Brook/Cole, Boston MA

Voyer, D and Voyer, S. D (2014) Gender Differences in Scholastic Achievement: A Meta-Analysis, Psychological Bulletin 1404 pp 1174-1204

WEF (2014) Global Gender Gap Report 2014 available at http://reports.weforum.org/global-gender-gap-report-2014/ [accessed 09.10.2015] 